Western University

Scholarship@Western

Chemistry Publications

Chemistry Department

$4-2018$

\title{
Group 13 Complexes of Chelating N2O2n- Ligands as Hybrid Molecular Materials
}

Ryan R. Maar

Western University

Joe B. Gilroy

Western University, joe.gilroy@uwo.ca

Follow this and additional works at: https://ir.lib.uwo.ca/chempub

Part of the Chemistry Commons

Citation of this paper:

Maar, Ryan R. and Gilroy, Joe B., "Group 13 Complexes of Chelating N2O2n- Ligands as Hybrid Molecular Materials" (2018).

Chemistry Publications. 93.

https://ir.lib.uwo.ca/chempub/93 


\section{Group 13 Complexes of}

Chelating $\mathrm{N}_{2} \mathrm{O}_{2}{ }^{\mathrm{n}-}$ Ligands as

\section{Hybrid Molecular Materials}

Ryan R. Maar ${ }^{[a]}$ and Joe B. Gilroy*[a]

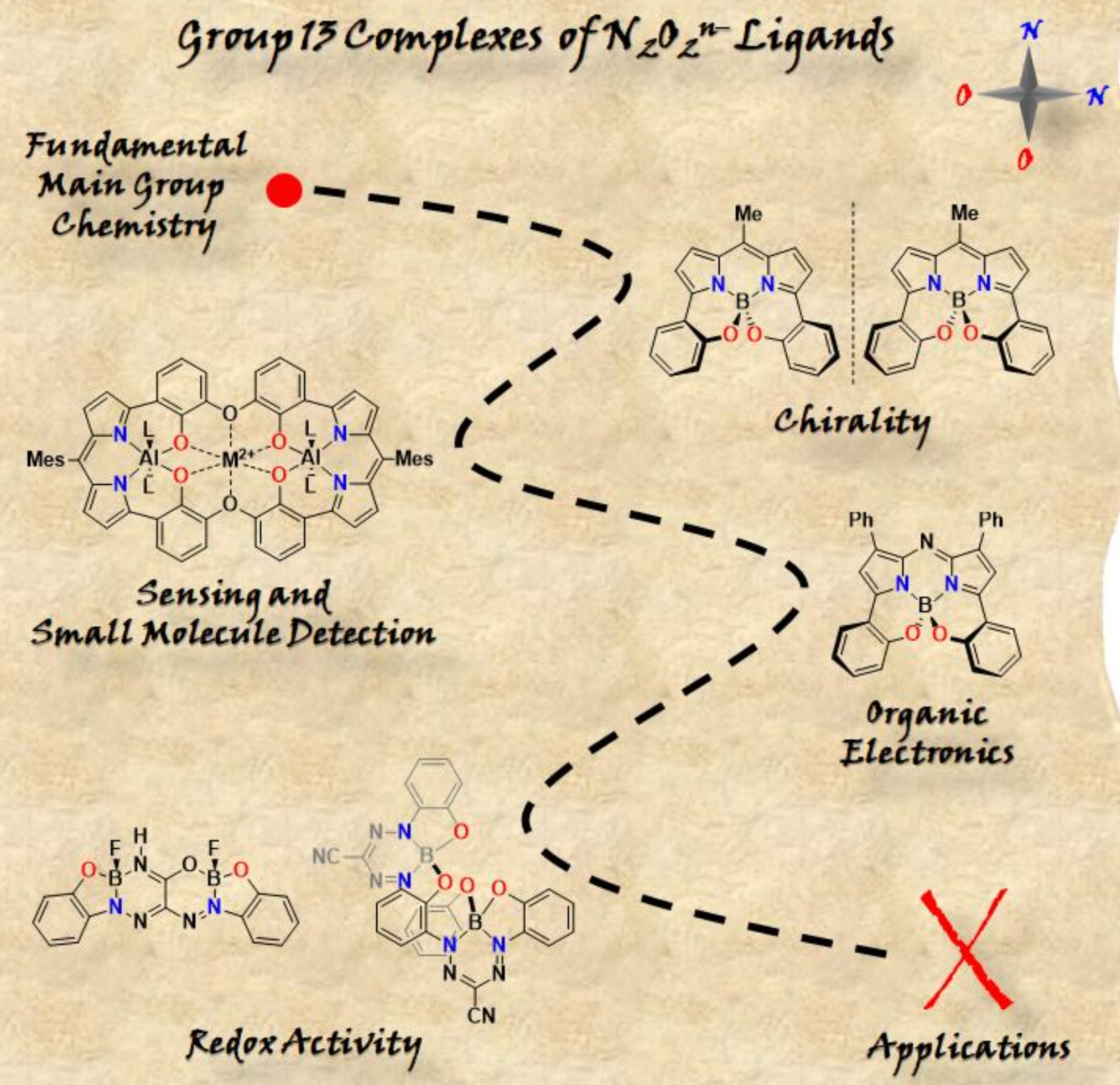


Abstract: Recent synthetic advances have afforded opportunities for the creation of a wide range of potentially tetradentate $\mathrm{N}_{2} \mathrm{O}_{2}{ }^{\mathrm{n}-}$ ligands. When combined with group 13 elements, robust functional molecular materials can be realized. This concept article describes advances surrounding group 13 complexes of selected families of $\mathrm{N}_{2} \mathrm{O}_{2}{ }^{\mathrm{n}-}$ ligands, including examples with unique chirality, sensing/detection capabilities, utility in organic electronics, and redox properties. It also highlights the bridge between fundamental main group chemistry and useful application that is being established within this research field.

\section{Introduction}

In this concept article, we focus on selected examples of group 13 complexes of $\mathrm{N}_{2} \mathrm{O}_{2}{ }^{\mathrm{n}-}$ ligands with unusual chirality, ${ }^{[1-2]}$ sensing/detection capabilities, ${ }^{[3-11]}$ utility in organic electronics, ${ }^{[12-}$ ${ }^{15]}$ and redox activity. ${ }^{[16-17]}$ The use of $\mathrm{N}_{2} \mathrm{O}_{2}{ }^{\mathrm{n}-}$ ligands in main group coordination chemistry affords opportunities to exploit the chelate effect, and often results in the production of stable and robust complexes. The addition of nitrogen/oxygen atoms to $\pi$ conjugated ligands can lead to extended electronic delocalization and stabilized frontier orbitals in the resulting complexes. Group 13 elements are advantageous in this context as they can promote rigidity and induce chirality when coordinated to $\mathrm{N}_{2} \mathrm{O}_{2}{ }^{\mathrm{n}-}$ ligands via strong covalent bonds to oxygen and nitrogen. This structural control allows for modulation of the optoelectronic properties of the resulting complexes and takes advantage of the well-defined coordination geometries (i.e., tetrahedral, square pyramidal, octahedral) associated with group 13 elements.

Below, we highlight selected examples that combine these traits and incorporate boron, ${ }^{[1-4,8-9,13-16,18-25]}$ and aluminum, ${ }^{[5-8,10-}$ $12,17,26-33]$ and ligands derived from dipyrrins (e.g., 1) and azadipyrrins (e.g., 2) ${ }^{[34-38]}$ formazans (e.g., 3), ${ }^{[39-40]}$ and Schiff base ligands (e.g., 4). ${ }^{[41-42]}$ The absence of examples based on familiar ligand-types such as $\beta$-diketiminates relates to synthetic limitations ${ }^{[23]}$ while those linked to catalysis have been reviewed elsewhere. ${ }^{[43-44]}$

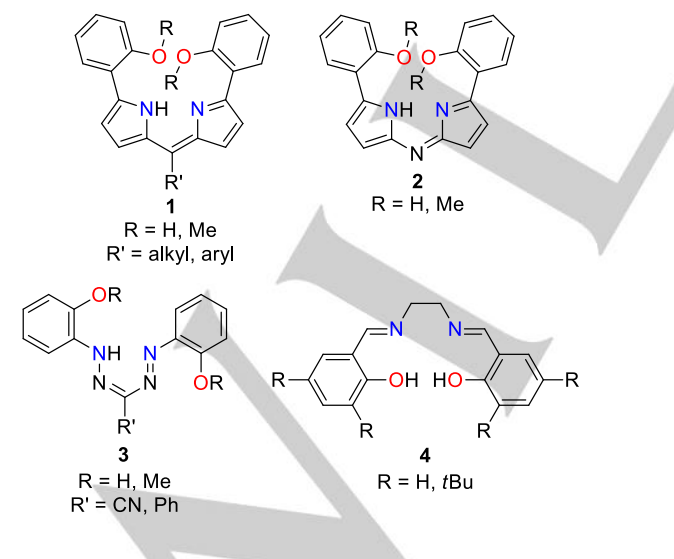

[a] Mr. Ryan R. Maar, Prof. Dr. Joe B. Gilroy

Department of Chemistry and the Centre for Advanced Materials and Biomaterials Research (CAMBR)

The University of Western Ontario

1151 Richmond St. N., London, Ontario, Canada, N6A 5B7

E-mail: joe.gilroy@uwo.ca

\section{Chiral Luminescent Materials}

Growing interest in the development of simple molecular materials that exhibit circularly polarized photoluminescence (CPL) has been driven by their chiroptics (i.e., chiral optics). These materials have potential application as the active component of $3 \mathrm{D}$ displays, in information storage technologies where wavelength, intensity, and chirality information can be exploited, and in spintronics-based devices. ${ }^{[45]}$

Two of the key parameters associated with optimized CPL are the photoluminescence $(P L)$ dissymmetry factor $\left(\left|g_{\mathrm{lum}}\right|\right)$, which indicates the degree of polarization, and the PL quantum yield $\left(\Phi_{\mathrm{PL}}\right)$, which quantifies the intensity of the PL. Boron complexes of dipyrrinate ligands are promising candidates in this regard, as the tetrahedral geometry at boron has the potential to induce helical chirality within the ligand framework. Inspired by the early work of the Burgess group ${ }^{[46]}$ a team led by Knight and Hall developed a family of boron complexes of $\mathrm{N}_{2} \mathrm{O}_{2}{ }^{3-}$ dipyrrinate ligands that exhibited CPL. ${ }^{[1]}$ For example, a racemic mixture of $P / M$-isomers (i.e., $\Delta / \Lambda$-isomers) of complex $\mathbf{5}$ was prepared via a multistep pathway. Suzuki cross-coupling between tert-butyl-2bromo-1 $\mathrm{H}$-pyrrole-1-carboxylate and (2-hydroxyphenyl)boronic acid followed by alkaline hydrolysis afforded 2- $(1 \mathrm{H}-$ pyrrol-2$\mathrm{yl})$ phenol, which was condensed with triethyl orthoformate under acidic conditions and reacted with boron trifluoride diethyl etherate to afford complex 5 (Figure 1a).

The $P$ - and $M$-isomers of 5 were resolved by semipreparative chiral HPLC to allow for their chiroptical properties to be examined. Figure $1 \mathrm{~b}$ includes normalized circular dichroism (CD) spectra for each isomer and a normalized UV-vis absorption spectrum. Through simulation of these data, the authors assigned the absolute configuration of each isomer. The $\mathrm{CPL}$ and PL spectra (Figure 1c) afforded $\left|g_{\mathrm{lum}}\right|=4.7 \times 10^{-3}$ and $\Phi_{\mathrm{PL}}=0.65$ in acetonitrile. The value of $\Phi_{\mathrm{PL}} \cdot\left|g_{\mathrm{lum}}\right|=3.1 \times 10^{-3}$, provides an indication of the overall CPL quantum efficiency. At the time of publication, complex $\mathbf{5}$ was the most efficient, redemitting single-fluorophore reported to date.

The Nabeshima group developed a dimeric compound 6 containing two $\mathrm{N}_{2} \mathrm{O}_{2}$ pockets to further exploit helical chirality in dipyrrin-based boron complexes. ${ }^{[2]}$ Reaction of 6 with excess phenylboronic acid afforded complex 7 which featured a figureof-eight helical structure due to boron's propensity to adopt a tetrahedral geometry. The racemic solid-state structure of 7 confirmed that each of the $\mathrm{N}_{2} \mathrm{O}_{2}{ }^{3-}$ dipyrrinate moieties adopt the same helical chirality (i.e., $P, P$ - or $M, M$-isomers). The asymmetric unit contained two closely related molecules revealing dihedral angles of $158.4^{\circ}$ and $155.8^{\circ}$ between the planes of the dipyrrinate cores.

The $P, P$ - and $M, M$-isomers were resolved using chiral HPLC and the former was studied using CD and UV-vis absorption spectroscopy, revealing maxima at $639 \mathrm{~nm}$ and $631 \mathrm{~nm}$ in chloroform, respectively. The CPL spectrum recorded for $P, P-7$ contained a band centered at $663 \mathrm{~nm}$, and with $\left|g_{\text {lum }}\right|=9 \times 10^{-3}$, a considerable value for a small molecule of this type. Crucially, this value was three times that determined for an analogous monomeric species. This demonstrated a synergistic effect associated with the figure-of-eight conformation adopted by the ligand backbone in $P, P-7$ and that the chiroptical properties observed are not simply the summation of the properties of two independent boron complexes of the $\mathrm{N}_{2} \mathrm{O}_{2}{ }^{3-}$ dipyrrinate ligands involved. The $\Phi_{\mathrm{PL}}$ for $P, P-7$ was 0.58 
a
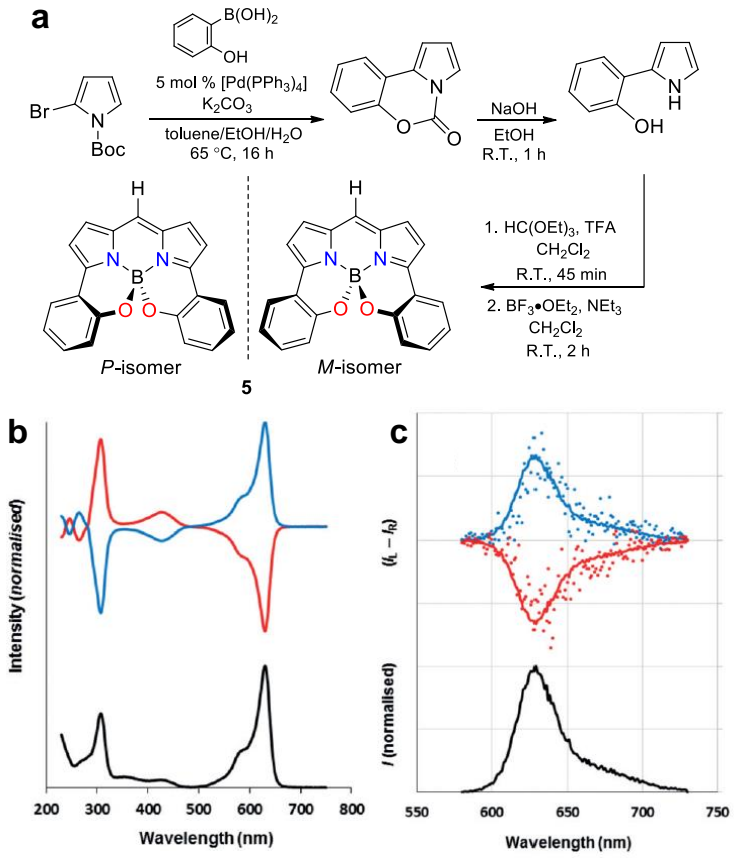

Figure 1. (a) Synthesis of a racemic mixture of boron complexes 5. (b) Normalized CD spectra for $P-5$ (blue) and $M-5$ (red) and normalized UV-vis absorption spectra (black). (c) Normalized CPL spectra for P-5 (blue) and $M-5$ (red) and normalized PL spectra (black). TFA = trifluoroacetic acid. Figure adapted from Ref. [1] with permission. Copyright Wiley 2016.

and the value of $\Phi_{\mathrm{PL}} \cdot\left|g_{\text {lum }}\right|=5.3 \times 10^{-3}$ sets the stage for the use of these compounds in applications based on chiroptical properties mentioned above.

\section{Materials for Sensing and Small Molecule Detection}

Group 13 complexes of $\mathrm{N}_{2} \mathrm{O}_{2}{ }^{\mathrm{n}-}$ ligands have shown utility in sensing applications and for the detection of small molecules. Examples can be classified into two categories, those where the $\mathrm{N}_{2} \mathrm{O}_{2}{ }^{\mathrm{n}-}$ ligands modulate reactivity at the group 13 element allowing for adducts to be formed and detected, ${ }^{[7,11]}$ and those that exploit changes in the physical properties of group 13 complexes of $\mathrm{N}_{2} \mathrm{O}_{2}{ }^{\mathrm{n}-}$ ligands upon interaction with small molecules. ${ }^{[3-6,8-10]}$

Nerve agents such as Sarin and VX are organophosphonate derivatives that irreversibly bind to the catalytic site of acetylcholinesterase, an enzyme that hydrolyzes the neurotransmitter acetylcholine. ${ }^{[4]}$ Their detection is complicated by degradation on the hour timescale, often to related toxic species that must be functionalized prior to analysis by integrated chromatography/mass spectrometry methods.

The Atwood group developed a strategy for the detection of these nerve agents based on the versatile coordination chemistry of aluminum supported by an $\mathrm{N}_{2} \mathrm{O}_{2}{ }^{2-}$ Salen ligand [N, $N$ '-alkylene bis(3,5-di-tert-butylsalicylideneimine)] in aqueous solution using electrospray ionization mass spectrometry (ESIMS) (Figure 3) ${ }^{[7]}$ SalenAlBr complex $8^{[26]}$ was transformed to the bis aqua adduct 9 in aqueous solution via loss of the bromide anion. The key species for nerve agent detection was formed via reaction of the six-coordinate complex 9 with ammonium acetate, to form the five-coordinate acetate adduct 10 . While computational studies showed that the displacement of the

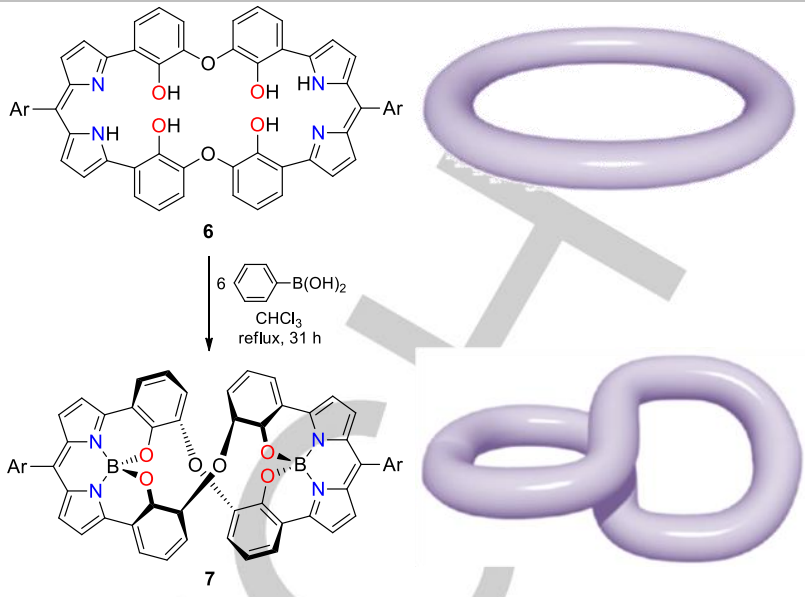

Figure 2. Synthesis of dimeric boron complex 7 ( $P, P$-isomer shown) and corresponding cartoon representations of the ligand backbones. $\mathrm{Ar}=2,4,6$ trimethylphenyl. Figure adapted from Ref. [2] with permission. Copyright Royal Society of Chemistry 2016.

acetate group from the complex by the nerve agents was not energetically favorable, the authors postulated that this reaction was driven by the hydrophobicity of the nerve agents themselves. Specifically, Sarin $\left(\mathrm{R}=\mathrm{CHMe}_{2}, \mathrm{X}=\mathrm{F}\right)$, Soman $[\mathrm{R}=$ $\left.\mathrm{CH}(\mathrm{Me}) \mathrm{CMe}_{3}, \quad \mathrm{X}=\mathrm{F}\right]$, and the hydrolysate of $\mathrm{VX}$, ethylmethylphosphonic acid (EMPA, $R=E t, X=O H$ ) were found to coordinate to the SalenAl ${ }^{+}$fragment via an oxygen lone pair of the phosphate group to yield cationic complexes (11). The resulting complexes were readily detected by ESI-MS and circumvented the need for functionalization and chromatography prior to analysis.

The host-guest chemistry of crown ethers has fascinated supramolecular chemists for decades and prompted many studies of the relationship between structure and cation binding specificity. ${ }^{[48]}$ Nabeshima's research team have developed a hybrid crown ether based on octahedral aluminum complexes of the dimeric dipyrrin 6 (Figure 4). ${ }^{[8]}$ Complex 12, which benefits from enhanced rigidity and planarity relative to the parent ligand as a direct result of coordination to aluminum, effectively binds alkaline earth metals to yield host-guest complexes $12 \cdot \mathrm{M}^{2+}$. It has higher affinity for $\mathrm{Ca}^{2+}$ and $\mathrm{Sr}^{2+}$ than classical crown ethers 13 and 14. ${ }^{[49]}$ This system also benefited from the presence of intense low-energy absorption bands in solution, allowing for cation binding to be monitored via UV-vis

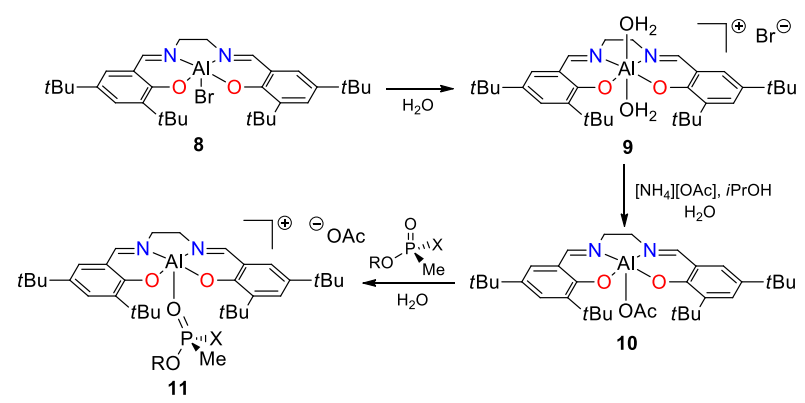

Figure 3. Reaction sequence required for the production of five-coordinate aluminum adducts of the nerve agents Sarin $\left(R=\mathrm{CHMe}_{2}, X=F\right)$, Soman $[R=$ $\left.\mathrm{CH}(\mathrm{Me}) \mathrm{CMe}_{3}, \mathrm{X}=\mathrm{F}\right]$, and the hydrolysate of $\mathrm{VX}(\mathrm{EMPA}, \mathrm{R}=\mathrm{Et}, \mathrm{X}=\mathrm{OH}$ ) allowing for their detection by ESI-MS. ${ }^{[7]}$ 
Table 1. Binding constants for the interactions between host crown ethers 1214 and alkaline earth metal guests expressed as log $K_{\mathrm{a}}$

\begin{tabular}{lccc}
\hline & $12^{[8]}$ & $13^{[49]}$ & $14^{[49]}$ \\
\hline $\mathrm{Mg}^{2+}$ & $2.8^{[\mathrm{a}]}$ & $3.6^{[\mathrm{c}]}$ & $2.3^{[\mathrm{cc}]}$ \\
$\mathrm{Ca}^{2+}$ & $>7^{[\mathrm{b}]}$ & $4.3^{[\mathrm{c}]}$ & $2.8^{[\mathrm{c}]}$ \\
$\mathrm{Sr}^{2+}$ & $>7^{[\mathrm{b}]}$ & $5.6^{[\mathrm{c}]}$ & $3.5^{[\mathrm{c}]}$ \\
$\mathrm{Ba}^{2+}$ & $6.4^{[\mathrm{b}]}$ & $7.2^{[\mathrm{c}]}$ & $4.4^{[\mathrm{c}]}$
\end{tabular}

Solvents used for binding study (v/v): [a] $\mathrm{CH}_{3} \mathrm{OH} / \mathrm{H}_{2} \mathrm{O}=$ 9:1. [b] $\mathrm{CH}_{3} \mathrm{OH} / \mathrm{H}_{2} \mathrm{O} / \mathrm{CHCl}_{3}=89.5: 10: 0.5$. [c] $\mathrm{MeOH}$.
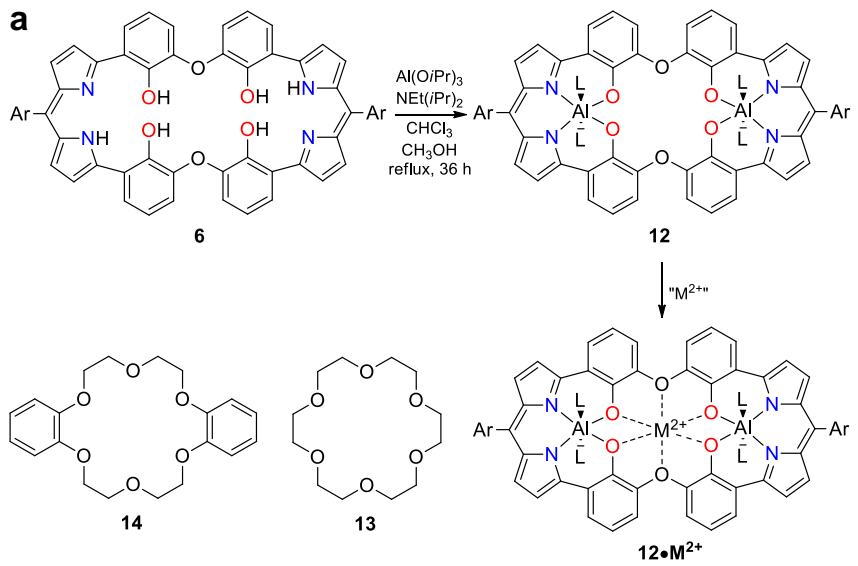

b

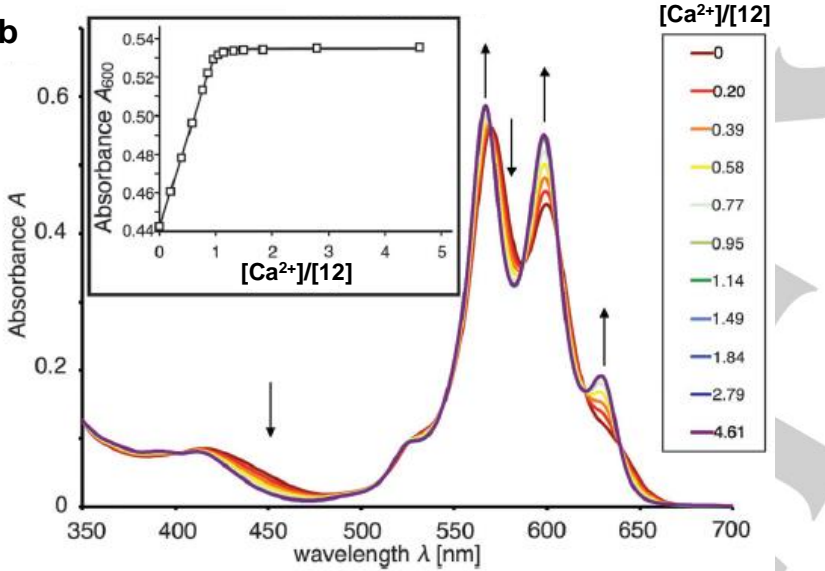

Figure 4. (a) Synthesis and host-guest chemistry of hybrid crown ether 12 and structures of crown ethers 13 and 14. (b) UV-vis absorption spectra recorded upon addition of $[\mathrm{Ca}]\left[\mathrm{ClO}_{4}\right]_{2}$ to $12(5.0 \mu \mathrm{M})$ in a 89.5:10:0.5 mixture of $\mathrm{CH}_{3} \mathrm{OH} / \mathrm{H}_{2} \mathrm{O} / \mathrm{CHCl}_{3}$. The inset shows the change in absorption intensity at 600 $\mathrm{nm}$ upon addition of of $[\mathrm{Ca}]\left[\mathrm{ClO}_{4}\right]_{2}$. Ar $=2,4,6$-trimethylphenyl, $\mathrm{L}=\mathrm{MeOH}$. Figure adapted from Ref. [8] with permission. Copyright Royal Society of Chemistry 2016

absorption spectroscopy. The intensity of the absorption peak centered at ca. $600 \mathrm{~nm}\left(\varepsilon \sim 9 \times 10^{4} \mathrm{M}^{-1} \mathrm{~cm}^{-1}\right)$ increased upon binding of alkaline earth metals such as $\mathrm{Ca}^{2+}$, to a maximum absorbance at a $\left[\mathrm{Ca}^{2+}\right]:[12]$ ratio of 1 (Figure 4b). Through judicious design, the authors of this study demonstrated that aluminum complexes of dimeric $\mathrm{N}_{2} \mathrm{O}_{2}{ }^{3-}$ dipyrrinate ligands are promising candidates for small molecule sensing.

\section{Materials for Organic Electronics}

Selected examples of group 13 complexes of $\mathrm{N}_{2} \mathrm{O}_{2}{ }^{\mathrm{n}-}$ ligands have shown utility in organic electronic devices such as organic light-emitting diodes (OLEDs) ${ }^{[12]}$ and solar cells ${ }^{[13-15]}$ due to their film-forming and photophysical properties.

The synthesis of $\mathrm{N}_{2} \mathrm{O}_{2}$ aza-dipyrrin 15 and its conversion to the corresponding tetrahedral boron complex 16 are shown in Figure $5 a^{[18]}$ Complex $\mathbf{1 6}$ is well suited as a donor material in solar cell as it possesses exceptional light harvesting capability with extinction coefficients near $1 \times 10^{5} \mathrm{M}^{-1} \mathrm{~cm}^{-1}$ in solution and broad absorption bands spanning most of the visible region, including the near-IR (nIR). The research team led by $\mathrm{Ma}$ demonstrated its efficacy as a hole carrier, recording mobilities up to $2 \times 10^{-4} \mathrm{~cm}^{2} \mathrm{~V}^{-1} \mathrm{~s}^{-1}$ for thin films prepared from chlorobenzene. ${ }^{[13]}$ They further tested device performance by constructing planar heterojunction solar cells with the following structure: indium tin oxide (ITO)/ poly(styrene sulfonate) doped poly(3,4-ethyhlene-dioxythiophene) (PEDOT:PSS, $40 \mathrm{~nm}) / \mathbf{1 6}$ $(8-15 \mathrm{~nm}) / \mathrm{C}_{60}(45 \mathrm{~nm}) /$ bathocuproine $(\mathrm{BCP}, 10 \mathrm{~nm}) / \mathrm{Ag}(100$ $\mathrm{nm})$. Triplicate analysis of the devices revealed several important characteristics, including high open circuit voltages of $\sim 0.8 \mathrm{~V}$, photocurrent generation up to $850 \mathrm{~nm}$, fill factors of 0.56 , and average/maximum optimized power conversion efficiencies of $2.53 \% / 2.63 \%$ (Figure $5 \mathrm{~b}$ ). The latter was the highest value reported for planar heterojunction solar cells based on $\mathrm{nIR}$ donors at the time. Coordination of boron to aza-dipyrrin 15 resulted in enhanced solar cell performance, including a five-fold increase in power conversion efficiency compared to identical cells based on $\mathbf{1 5}$ as the donor material. This improved performance is likely the direct result of structural rigidity imparted upon coordination to boron.

Starting from SalenAIMe 17 and octahedral iridium complex 18, Do and co-workers prepared heterodinuclear complex 19, which combined the photophysical properties of aluminum Salen complexes with those of octahedral, cationic iridium(III) complexes (Figure 6a). ${ }^{[12]}$ In solution, the room temperature PL spectrum collected for $\mathbf{1 9}$ was comprised of two intense maxima. These maxima matched well with the wavelengths of maximum PL intensity observed for complex $\mathbf{1 7}$ $(475 \mathrm{~nm})$ and iridium complex $18(596 \mathrm{~nm})$. The independent PL properties observed for each structural component of 19 may result from the orthogonal arrangement of the individual luminophores achieved by exploiting the ability of aluminum to

a
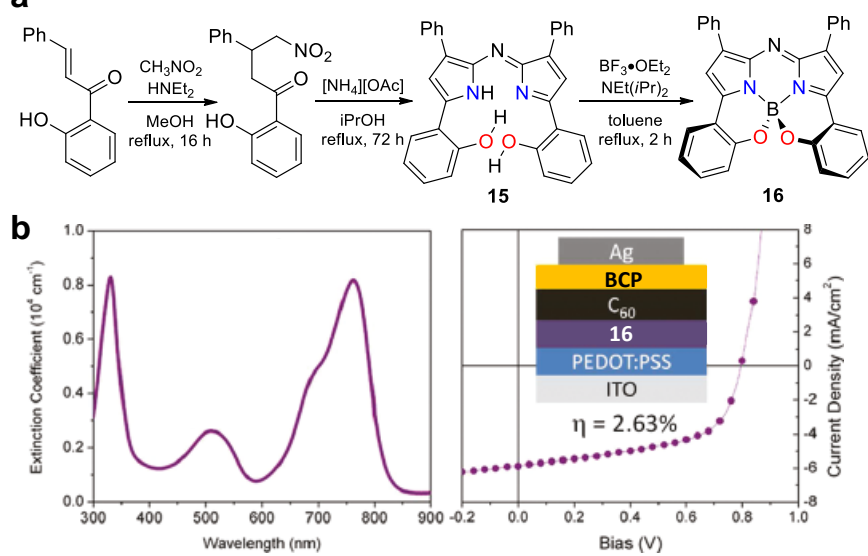

Figure 5. (a) Synthesis of $\mathrm{N}_{2} \mathrm{O}_{2}$ aza-dipyrrin 15 and its boron complex 16. ${ }^{[18]}$ (b) UV-vis absorption spectrum of a thin film of complex 16 (left) and device architecture (inset) and representative current density-voltage (J-V) characteristics of a device incorporating complex 16 under AM 1.5G simulated 1 sun solar illumination (right). Figure adapted from Ref. [13] with permission. Copyright American Chemical Society 2011. 
form stable five-coordinate complexes (Figure 6b). Furthermore, the lifetimes of the PL maxima centered at 475 and $596 \mathrm{~nm}$ were determined to be $<10$ ns and $196 \mathrm{~ns}$, respectively. This confirmed that the PL associated with the 'SalenAl' portion of 19 was produced via fluorescence, while the low-energy maximum associated with the portion of the structure based on the octahedral iridium complex was generated via phosphorescence. Upon cooling to $77 \mathrm{~K}$, the maxima were blue-shifted and the relative intensity of the low-energy peak increased, indicating the occurrence of intramolecular energy transfer from the 'SalenAl' fragment to the octahedral iridium center. In the solid state, a single PL maximum at $583 \mathrm{~nm}$ was observed, suggesting highly efficient energy transfer.

An OLED was prepared with the following architecture: ITO/PEDOT:PSS $(40 \mathrm{~nm}) / \mathbf{1 9} \quad(40 \mathrm{~nm}) / \mathrm{BCP} \quad(20 \mathrm{~nm}) / \operatorname{tris}(8$ hydroxyquinolinato)aluminum $\left(\mathrm{Alq}_{3}, 20 \mathrm{~nm}\right) / \mathrm{LiF}(1 \mathrm{~nm}) / \mathrm{Al}(100$ $\mathrm{nm}$ ), where the emitting layer of 19 was spin-coated from 1,2dichloroethane solution. Analysis of the OLED revealed many attractive features such as a low turn-on voltage of $3.4 \mathrm{~V}$ attributed to the ionic nature of complex 19, which enhanced charge transport in the solid state. Consistent with the solid-state $\mathrm{PL}$ properties of 19, the OLEDs emitted at $600 \mathrm{~nm}$ with Commission Internationale de L'Eclairage (CIE) colour coordinates of $(0.54,0.46)$ that were essentially unchanged with variation of current density. The OLED had maximum brightness $\left(L_{\max }\right)$ of $1002 \mathrm{~cd} \mathrm{~m}^{-2}$ at $10.8 \mathrm{~V}$, a luminance efficiency $(\eta \mathrm{L})$ of $1.8 \mathrm{~cd} \mathrm{~A}^{-1}$, external quantum efficiency (EQE) of $0.94 \%$, and a luminous efficiency (LPW) of $0.69 \mathrm{Im} \mathrm{W}^{-1}$ at $8.2 \mathrm{~V}$. The authors noted that this OLED significantly outperformed those prepared with identical device architectures and luminescent layers comprised of only structurally related SalenAl complexes and/or octahedral iridium complexes.

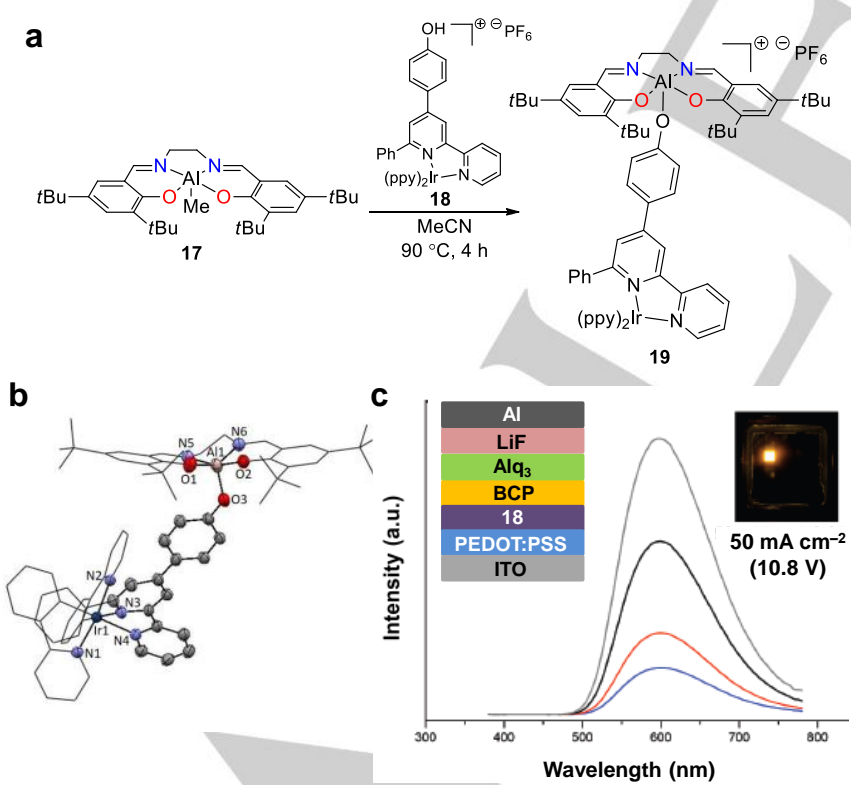

Figure 6. (a) Synthesis of heterodinuclear complex 19. (b) Solid-state structure of complex 19. Thermal displacement ellipsoids are shown at the $50 \%$ probability level. Hydrogen atoms omitted and selected structura components presented as wireframe for clarity. (c) OLED device architecture (left inset), photograph of working OLED (right inset), and electroluminescence spectra of an OLED based on complex 19 collected at $10 \mathrm{~mA} \mathrm{~cm}^{-2}$ (blue line), $20 \mathrm{~mA} \mathrm{~cm}^{-2}$ (red line), $50 \mathrm{~mA} \mathrm{~cm}^{-2}$ (black line), and $100 \mathrm{~mA} \mathrm{~cm}^{-2}$ (grey line). ppy $=2$-phenylpyridine. Figure adapted from Ref. [12] with permission. Copyright American Chemical Society 2008.

\section{Redox-Active Materials}

In addition to many of the properties highlighted above, group 13 complexes of ligands derived from formazans offer rich redox chemistry. ${ }^{[50-53]}$ Boron and aluminum complexes of $\mathrm{N}_{2} \mathrm{O}_{2}{ }^{3-}$ formazanate ligands are relatively straightforward to synthesize, and have been used as electrochemiluminescence (ECL) emitters ${ }^{[17]}$ and as precursors to redox-active BN heterocycles. ${ }^{[16]}$

Formazan 20 can be synthesized in a single step from cyanoacetic acid and two equivalents of the aryldiazonium salt, prepared from 2-aminophenol, under basic conditions. The formazan can be converted to the corresponding aluminum formazanate complex $\mathbf{2 1}$ by heating in the presence of aluminum iso-propoxide and triphenylphosphine oxide (Figure 7a) ${ }^{[17]}$ It was demonstrated that variation of the phosphine oxide ligands in complexes similar to $\mathbf{2 1}$ did not significantly affect their properties. Complex 21, which benefited from increased rigidity and polarity upon coordination to aluminum, was both redox active and emissive, prompting studies of its ECL in the presence of tri- $n$-propylamine (TPrA). The (electro)chemical reactions implicated in the ECL observed for $\mathbf{2 1}$ are shown in Figure $7 \mathrm{~b}$ (equations 1-5) and the ECL spooling spectra collected at time intervals of $2 \mathrm{~s}$ are shown in Figure 7c. The key to this experiment is the simultaneous oxidation of TPrA and complex 21. Upon scanning to positive potentials, the onset of ECL was observed at $0.26 \mathrm{~V}$ and a maximum intensity was reached at $0.51 \mathrm{~V}$. At these potentials TPrA is oxidized to TPrA ${ }^{\cdot+}$, which rapidly loses $\mathrm{H}^{+}$to form the potent reducing agent TPrA (equations 1 and 2). At these potentials, $\mathbf{2 1}$ is also oxidized to its

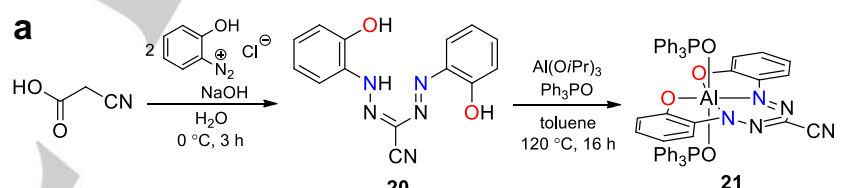

20

$$
\begin{aligned}
& \text { b } \quad \operatorname{TPRA} \stackrel{-\mathrm{e}^{-}}{\longrightarrow} \operatorname{TPr} \mathrm{A}^{\circ+} \\
& \operatorname{TPrA}^{0^{+}} \stackrel{-\mathrm{H}^{+}}{\longrightarrow} \operatorname{TPrA}{ }^{\circ} \\
& 21 \stackrel{-\mathrm{e}^{-}}{\longrightarrow} 21^{\circ} \\
& 21^{0^{+}+} \operatorname{TPrA}^{*} \longrightarrow 21^{*}+\mathrm{Pr}_{2} \stackrel{\oplus}{\mathrm{N}}=\mathrm{CHCH}_{2} \mathrm{CH}_{3} \\
& 21^{*} \underset{h v}{\longrightarrow} 21
\end{aligned}
$$

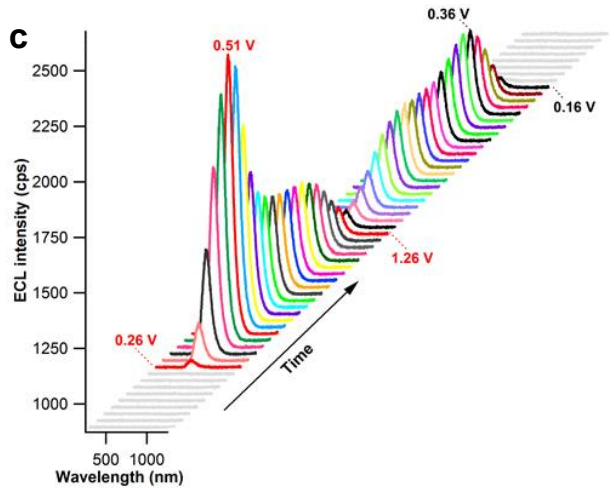

Figure 7. (a) Synthesis of phosphine oxide supported aluminum formazanate complex 21. (b) Reactions implicated in the generation of electrochemiluminescence from complex $\mathbf{2 1}$ in the presence of tri- $n$ propylamine (TPrA). (c) Spooling ECL spectra obtained for a dichloromethane solution containing $0.6 \mathrm{mM}$ of $\mathbf{2 1}, 5 \mathrm{mM}$ TPrA, $30 \mathrm{mM}$ triphenylphosphine oxide, and $0.1 \mathrm{M}\left[n \mathrm{Bu}_{4} \mathrm{~N}\right]\left[\mathrm{PF}_{6}\right]$ as supporting electrolyte acquired by reversibly scanning between $-0.24 \mathrm{~V}$ and $1.26 \mathrm{~V}$ at a scan rate of $25 \mathrm{mV} \mathrm{s}^{-1}$ and a time interval of $2 \mathrm{~s}$. Figure adapted from Ref. [17] with permission. Copyright American Chemical Society 2017 
radical cation form $\mathbf{2 1}^{\circ+}$ (equation 3 ). A redox reaction between TPrA and $21^{*+}$ generates the emissive excited state $\mathbf{2 1}^{*}$ (equation 4), which existed at maximum concentration at $0.51 \mathrm{~V}$. The excited state emits a photon upon relaxation to the ground state (equation 5). In the case of compound 21, ECL was centered at $735 \mathrm{~nm}$ with an efficiency of approximately $7 \%$ relative to the benchmark $\left[\mathrm{Ru}(\mathrm{bpy})_{3}\right]\left[\mathrm{PF}_{6}\right]_{2} / \mathrm{TPrA}$ system.

The reaction of formazan $\mathbf{2 0}$ and boron trifluoride diethyl etherate in the presence of base produced five novel BN heterocycles, including 22 and 23 (Scheme 1). ${ }^{[16]}$ The relatively smaller size of the boron atom compared to aluminum significantly influenced the structure of the compounds formed, including the notable absence of discrete boron complexes involving a single ligand bound to a tetrahedral boron atom.

Reduction of $\mathbf{2 2}$ with cobaltocene produced diamagnetic anion 24 via loss of $\mathrm{H}^{*}$ (Figure $8 \mathrm{a}$ ). The $\pi$-electron systems of complexes 22 and $\mathbf{2 4}$ are highly delocalized, as evidenced by their solid-state structures and HOMO and LUMO isosurfaces (Figure $8 \mathrm{~b}$ ). As a result, the complexes were strongly absorbing in the low-energy region of the visible spectrum, with the absorption band of $\mathbf{2 4}$ slightly red-shifted relative to that of $\mathbf{2 2}$ due to its anionic character [22: $\lambda_{\max }=577 \mathrm{~nm}\left(\varepsilon=35,900 \mathrm{M}^{-1}\right.$ $\left.\mathrm{cm}^{-1} ; 24: \lambda_{\max }=589 \mathrm{~nm}\left(\varepsilon=18,100 \mathrm{M}^{-1} \mathrm{~cm}^{-1}\right)\right]$.

The presence of two boron formazanate heterocycles in dimeric complex 23 offered unique opportunities for redox chemistry. As such, chemical reduction with one or two equivalents of cobaltocene resulted in the formation of radical anion $\mathbf{2 3}^{\circ-}$ and diradical dianion $\mathbf{2 3}^{* 2-}$ (Figure 9a). The most significant structural change upon chemical reduction was an elongation in the N-N bonds of the formazanate ligand backbone, as observed in their solid-state structures (Figure 9b). In complex 23, which is comprised of two neutral boron formazanate rings, the average N-N bond length was $1.314(3) \AA$. These bonds elongated to an average length of 1.366(3) $\AA$ when both rings were reduced to radical anions in $\mathbf{2 3}^{* 2-}$. Importantly, one of these rings in $\mathbf{2 3}^{--}$had an average length of $1.315(3) \AA$ while the second had an average length of $1.360(3) \AA$. These results provide an indication of the localized electronic structure of the individual heterocycles in these dimeric molecules, and also demonstrated our ability to perform redox chemistry at each boron formazanate unit independently. The UV-vis absorption spectra of the same compounds further supported the localization of the unpaired electron(s) in each boron formazanate heterocycle within the dimers (Figure 9c). Dimer 23 had a low-energy absorption maximum at $569 \mathrm{~nm}\left(20,500 \mathrm{M}^{-1}\right.$ $\mathrm{cm}^{-1}$ ), while diradical dianion $23^{* 2-}$ absorbed strongly at $477 \mathrm{~nm}$ $\left(39,200 \mathrm{M}^{-1} \mathrm{~cm}^{-1}\right)$ and $687 \mathrm{~nm}\left(8,200 \mathrm{M}^{-1} \mathrm{~cm}^{-1}\right)$. The radical anion $\mathbf{2 3}^{-}$showed characteristics consistent with those of both 23 and $23^{* 2-}$, again indicating that each radical was localized on a single boron formazanate unit and not delocalized over the entire dimeric framework.

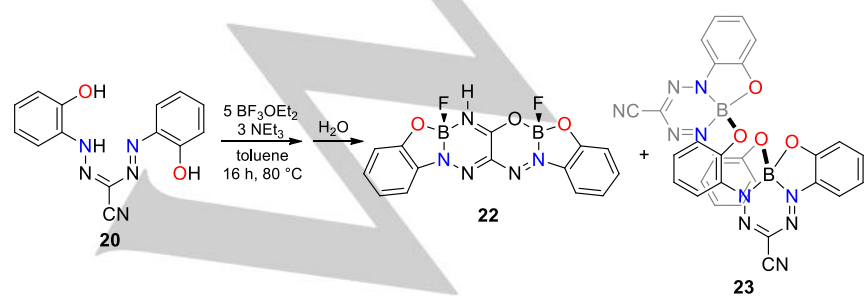

Scheme 1. Synthesis of BN heterocycles 22 and 23. ${ }^{[16]}$

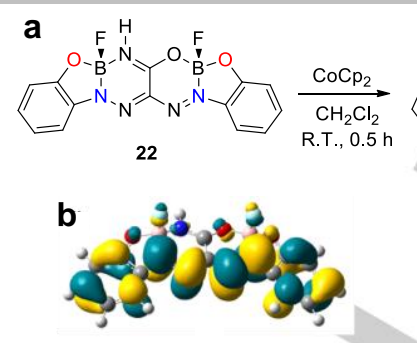

LUMO

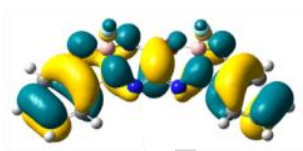

HOMO
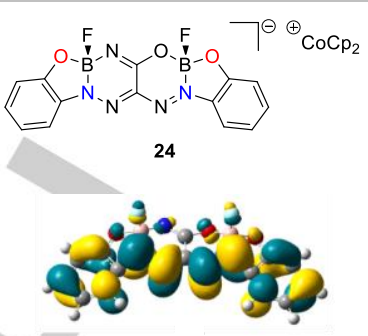

LUMO

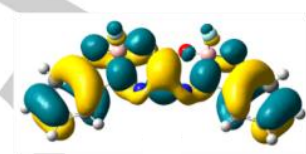

номо

Figure 8. (a) Chemical reduction of complex 22 to anion 24. (b) HOMOs and LUMOs for 22 and 24 calculated at the PBE1PBE/6-311+G(d,p) level. Figure adapted from Ref. [16] with permission. Copyright Wiley 2017.
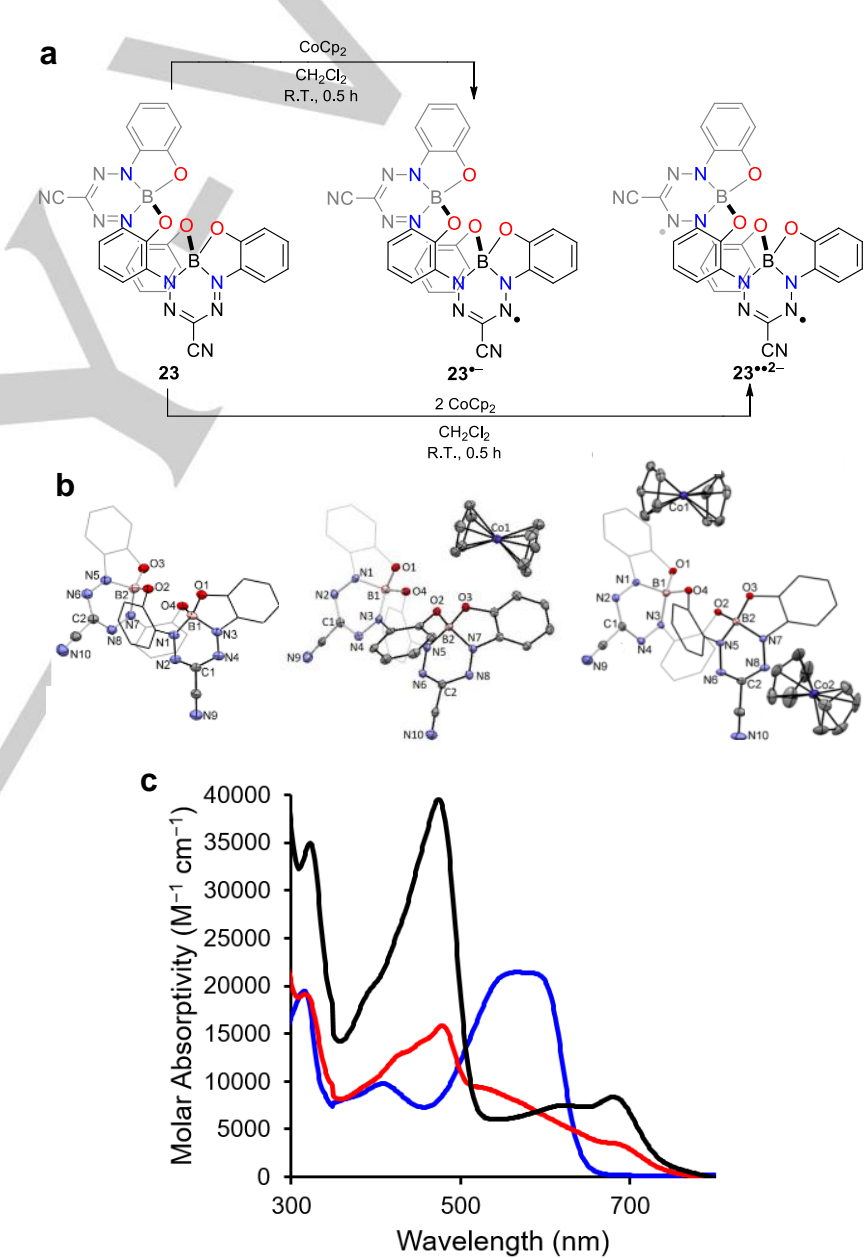

Figure 9. (a) Chemical reduction of complex 23 to radical anion $23^{--}$and diradical dianion $23^{* 2-}$. (b) Solid-state structures of $23,23^{\circ-}$, and $23^{* 2-}$. Thermal displacement ellipsoids are shown at the $50 \%$ probability level. Hydrogen atoms omitted and selected structural components presented as wireframe for clarity. (c) UV-vis absorption spectra recorded for $\mathbf{2 3}$ (blue line), $\mathbf{2 3}^{--}$(red line), and $\mathbf{2 3}^{\mathbf{*} 2-}$ (black line) in acetonitrile. Figure adapted from Ref. [16] with permission. Copyright Wiley 2017.

\section{Conclusions and Future Outlook}

The modulation and manipulation of the properties of $\mathrm{N}_{2} \mathrm{O}_{2}{ }^{\mathrm{n}}$ ligands via coordination to group 13 elements has emerged as a 
promising strategy for the preparation of hybrid molecular materials. In the past decade, examples with unique chirality, sensing and detection capabilities, utility in organic electronics, and redox-activity have emerged and paved the way for the future of this growing field.

Moving forward, there are many opportunities to combine the existing functionality of these systems to produce multifunctional molecular materials. For example, the information stored in chiral luminescent materials could be coupled with redox-activity to integrate switching properties. Additionally, the integration of different ligand types into dimeric and even trimeric structures, may allow for the selective binding of cations accompanied by changes in photophysical properties allowing for their use as next-generation sensors. Finally, and perhaps most importantly, a wide range of molecular materials should be produced and evaluated in organic electronic devices in order to move this field toward commercialization. We are certain that the future is promising for this unique class of molecular materials and look forward to upcoming reports by the groups highlighted in this concept article and others making important contributions to this exciting field.

\section{Acknowledgements}

We thank the Natural Sciences and Engineering Research Council (NSERC) of Canada (J.B.G.: DG RGPIN-2013-435675, R.R.M.: CGS-D Scholarship) for financial support.

Keywords: $\mathrm{N}_{2} \mathrm{O}_{2}{ }^{\mathrm{n}-}$ ligands $\cdot$ Hybrid Materials $\cdot$ Group $13 \cdot$ Main Group Chemistry $•$ Coordination Chemistry

[1] R. B. Alnoman, S. Rihn, D. C. O'Connor, F. A. Black, B. Costello, P. G. Waddell, W. Clegg, R. D. Peacock, W. Herrebout, J. G. Knight, M. J. Hall, Chem. Eur. J. 2016, 22, 93-96.

[2] M. Saikawa, T. Nakamura, J. Uchida, M. Yamamura, T. Nabeshima Chem. Commun. 2016, 52, 10727-10730

[3] A. K. Parhi, M.-P. Kung, K. Ploessl, H. F. Kung, Tetrahedron Lett. 2008 49, 3395-3399.

[4] J.-B. Chen, H.-X. Zhang, X.-F. Guo, H. Wang, H.-S. Zhang, Anal. Chim Acta 2013, 800, 77-86

[5] V. Béreau, C. Duhayon, J.-P. Sutter, Chem. Commun. 2014, 50, 12061-12064

[6] J. Cheng, X. Ma, Y. Zhang, J. Liu, X. Zhou, H. Xiang, Inorg. Chem. 2014, 53, 3210-3219.

[7] R. R. Butala, W. R. Creasy, R. A. Fry, M. L. McKee, D. A. Atwood, Chem. Commun. 2015, 51, 9269-9271.

[8] M. Saikawa, M. Daicho, T. Nakamura, J. Uchida, M. Yamamura, T. Nabeshima, Chem. Commun. 2016, 52, 4014-4017.

[9] J.-B. Chen, H.-X. Zhang, X.-F. Guo, H. Wang, H.-S. Zhang, Electrophoresis 2016, 37, 609-615.

[10] T. Khan, S. Vaidya, D. S. Mhatre, A. Datta, J. Phys. Chem. B 2016, 120, 10319-10326.

[11] J. Tang, H.-Y. Yin, J.-L. Zhang, Chem. Sci. 2018, 9, 1931-1939.

[12] J. O. Huh, M. H. Lee, H. Jang, K. Y. Hwang, J. S. Lee, S. H. Kim, Y. Do, Inorg. Chem. 2008, 47, 6566-6568.

[13] S. Y. Leblebici, L. Catane, D. E. Barclay, T. Olson, T. L. Chen, B. Ma, ACS Appl. Mater. Interfaces 2011, 3, 4469-4474.

[14] Y. Kubo, K. Watanabe, R. Nishiyabu, R. Hata, A. Murakami, T. Shoda, H. Ota, Org. Lett. 2011, 13, 4574-4577.

[15] S. Y. Leblebici, T. L. Chen, P. Oalde-Veasco, W. Yang, B. Ma, ACS Appl. Mater. Interfaces 2013, 5, 10105-10110.

[16] S. M. Barbon, V. N. Staroverov, J. B. Gilroy, Angew. Chem. Int. Ed. 2017, 56, 8173-8177.

[17] R. R. Maar, A. Rabiee Kenaree, R. Zhang, Y. Tao, B. D. Katzman, V. N Staroverov, Z. Ding, J. B. Gilroy, Inorg. Chem. 2017, 56, 12436-12447.
[18] A. Loudet, R. Bandichhor, K. Burgess, A. Palma, S. O. McDonnell, M. J. Hall, D. F. O'Shea, Org. Lett. 2008, 10, 4771-4774.

[19] Y. Kubo, Y. Minowa, T. Shoda, K. Takeshita, Tetrahedron Lett. 2010 $51,1600-1602$

[20] S. Rausaria, A. Kamadulski, N. P. Rath, L. Bryant, Z. Chen, D Salvemini, W. L. Neumann, J. Am. Chem. Soc. 2011, 133, 4200-4203.

[21] Y. Tornimori, T. Okujima, T. Yano, S. Mori, N. Ono, H. Yamada, H. Uno, Tetrahedron 2011, 67, 3187-3193.

[22] X. Ma, X. Jiang, S. Zhang, X. Huang, Y. Cheng, C. Zhu, Polym. Chem 2013, 4, 4396-4404.

[23] S. M. Barbon, V. N. Staroverov, P. D. Boyle, J. B. Gilroy, Dalton Trans 2014, 43, 240-250.

[24] S. Yamazawa, M. Nakashima, Y. Suda, R. Nishiyabu, Y. Kubo, J. Org Chem. 2016, 81, 1310-1315.

[25] J. Deschamps, Y. Chang, A. Langlois, N. Desbois, C. P. Gros, P. D. Harvey, New J. Chem. 2016, 40, 5835-5845.

[26] A. Mitra, L. J. DePue, S. Parkin, D. A. Atwood, J. Am. Chem. Soc. 2006 128, 1147-1153.

[27] C. Ikeda, S. Ueda, T. Nabeshima, Chem. Commun. 2009, 2544-2546.

[28] V. Béreau, V. Jubéra, P. Arnaud, A. Kaiba, P. Guionneau, J.-P. Sutter, Dalton Trans. 2010, 39, 2070-2077.

[29] V. Béreau, C. Duhayon, A. Soumia-Saquet, J.-P. Sutter, Inorg. Chem. 2012, 51, 1309-1318.

[30] M. E. M. Zayed, R. M. El-Shishtawy, Asian J. Chem. 2013, 25, 27192721.

[31] J. Luo, C. Zhang, X. Tang, W. Wang, H. Hu, B. Hu, Synth. Met. 2013 , $185,137-144$

[32] M. R. Shorkaei, Z. Asadi, M. Asadi, J. Mol. Struct. 2016, 1109, 22-30.

[33] T. Khan, A. Datta, J. Phys. Chem. C 2017, 121, 2410-2417.

[34] T. E. Wood, A. Thompson, Chem. Rev. 2007, 107, 1831-1861.

[35] A. Loudet, K. Burgess, Chem. Rev. 2007, 107, 4891-4932.

[36] D. Frath, J. Massue, G. Ulrich, R. Ziessel, Angew. Chem. Int. Ed. 2014 $53,2290-2310$.

[37] R. Sakamoto, T. Iwashima, M. Tsuchiya, R. Toyoda, R. Matsuoka, J. F. Kögel, S. Kusaka, K. Hoshiko, T. Yagi, T. Nagayama, H. Nishihara, J. Mater. Chem. A 2015, 3, 15357-15371.

[38] T. Nabeshima, M. Yamamura, G. J. Richards, T. Nakamura, J. Synth Org. Chem., Jpn. 2015, 73, 1111-1119

[39] A. W. Nineham, Chem. Rev. 1955, 55, 355-483.

[40] G. I. Sigeikin, G. N. Lipunova, I. G. Pervova, Russ. Chem. Rev. 2006 75, 885-900.

[41] A. W. Kleij, Eur. J. Inorg. Chem. 2009, 193-205.

[42] C. J. Whiteoak, G. Salassa, A. W. Kleij, Chem. Soc. Rev. 2012, 41, 622-631.

[43] P. G. Cozzi, Chem. Soc. Rev. 2004, 33, 410-421.

[44] A. Decortes, A. M. Castilla, A. W. Kleij, Angew. Chem. Int. Ed. 2010, 49, 9822-9837.

[45] E. M. Sánchez-Carnerero, A. R. Agarrabeitia, F. Moreno, B. L. Maroto G. Muller, M. J. Ortiz, S. de la Moya, Chem. Eur. J. 2015, 21, 1348813500.

[46] H. Kim, A. Burghart, M. B. Welch, J. Reibenspies, K. Burgess, Chem. Commun. 1999, 1889-1890.

[47] J. E. Chambers, S. F. Oppenheimer, Toxicol. Sci. 2004, 77, 185-187.

[48] R. M. Izatt, K. Pawlak, J. S. Bradshaw, R. L. Bruening, Chem. Rev. 1991, 91, 1721-2085.

[49] S. Kashanian, M. Shamsipur, Inorg. Chim. Acta 1989, 155, 203-206.

[50] J. B. Gilroy, M. J. Ferguson, R. McDonald, B. O. Patrick, R. G. Hicks, Chem. Commun. 2007, 126-128.

[51] M.-C. Chang, T. Dann, D. P. Day, M. Lutz, G. G. Wildgoose, E. Otten Angew. Chem. Int. Ed. 2014, 53, 4118-4122.

[52] R. Mondol, D. A. Snoeken, M.-C. Chang, E. Otten, Chem. Commun 2017, 53, 513-516.

[53] S. M. Barbon, S. Novoa, D. Bender, H. Groom, L. G. Luyt, J. B. Gilroy, Org. Chem. Front. 2017, 4, 178-190. 


\section{Entry for the Table of Contents}

\section{CONCEPT}

Recent advances surrounding group 13 complexes of selected $\mathrm{N}_{2} \mathrm{O}_{2}{ }^{\mathrm{n}-} \quad$ ligands, including examples with unique chiral luminescence, sensing/detection capabilities, utility in organic electronics, and redox properties are highlighted. We aim to demonstrate that the bridge between fundamental main group chemistry and useful application is being established by the unique opportunities within this field.

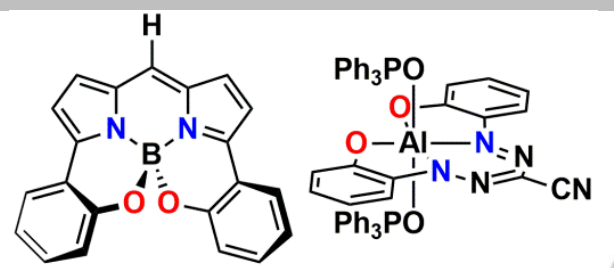

Ryan R. Maar, Joe B. Gilroy*

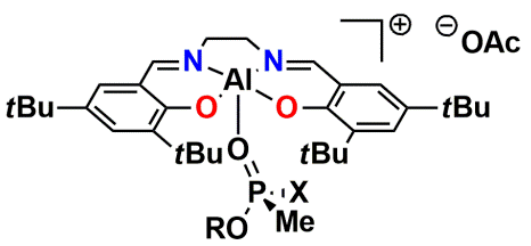

Page No. - Page No.

Group 13 Complexes of Chelating $\mathrm{N}_{2} \mathrm{O}_{2}{ }^{\mathrm{n}-}$ Ligands as Hybrid Molecular Materials 